\title{
Tools for Creating and Presenting Online Learning Resources for Preschool Kids
}

\author{
Vladimir Georgiev ${ }^{1}$, Alexandra Nikolova ${ }^{2}$ \\ ${ }^{1}$ Department of Computer Science, American University in Bulgaria, Bulgaria \\ ${ }^{2}$ Institute of Mathematics and Informatics, Bulgarian Academy of Sciences, Bulgaria
}

\begin{abstract}
This article introduces a module for presenting interactive learning resources for kids in online and mobile environments. Traditional eLearning systems are not suitable for children in preschool age, as they do not provide specific functionalities to meet the audience's presentation, interaction and focus requirements. To solve this problem, we propose a set of interactive software components for creating and visualizing lessons for kids, which can be integrated in existing and new eLearning platforms and mobile applications. The article describes the challenges of using learning management systems, points out the needs of the specific audience, and finally reveals the functionalities of a module for realizing learning resources for kids.
\end{abstract}

Keywords - e-Learning for Kids, Interactive Learning Resources, Learning Management System, Children Education.

\section{Introduction}

Electronic devices and the Internet are becoming more and more accessible to children of early age. Large percentage of kids has access to mobile phones and desktop computers, and show good intuition in using them. Since one's education begins from an early age, such technologies are important for supporting the learning process.

DOI: 10.18421/TEM94-49

https://doi.org/10.18421/TEM94-49

Corresponding author: Vladimir Georgiev, Department of Computer Science, American University in Bulgaria.

Email: vgeorgiev@aubg.edu

Received: 07 September 2020.

Revised: 22 October 2020.

Accepted: 27 October 2020.

Published: 27 November 2020.

(c) BY-NC-ND(C) 2020 Vladimir Georgiev \& Alexandra Nikolova; published by UIKTEN. This work is licensed under the Creative Commons AttributionNonCommercial-NoDerivs 4.0 License.

The article is published with Open Access at www.temjournal.com
Technologies are easily perceived by children, as they provide interactive, accessible and amusing content. Information technologies help kids improve their learning activities and acquire knowledge and skills in different areas, while seamlessly switching between theory and practice [1]. Practicing knowledge by playing games is what makes early education more acceptable.

Many children at early age use various IT instruments as part of their learning experience [2]. The growth and popularization of such technologies are continuously becoming an important part of the life of the younger generation, as there are several key areas where they are improving the learning process. Educational software keeps children more focused and concentrated on their own studies, allowing them to advance at their own pace and removing the need to synchronize with other peers in the classroom. All of the required material is easily accessible and constantly available on devices, which are controlled by adults and suitable for children. The use of software allows great flexibility, like instant navigation between topics, keeping track of the progress and increasing the level of awareness by using interactive graphics, video and other media types. That also stimulates participation, which might not be possible in a real classroom environment. As technology is an integral part of this era, its correct application for children development is required.

Currently there is a variety of e-Learning systems, but they are all targeted to higher education, professional or special topic courses. There is no platform that is suitable for presenting educational resources of different fields to children of young age, as they have different skills and needs. Educational platforms for kids should allow full interactivity with the other participants in the process, like the tutor and the pupils. It is important for kids to feel as they are part of the environment and to be able to examine and interact with all its components. Existing online learning platforms offer different types of features, like creating classrooms, adding, sharing and presenting resources, assessment and etc., but neither of these functionalities is interactive enough to be used by children. 
In this article we introduce a set of instruments, ready to be integrated in online learning environments for kids. The tools we have developed are interactive and specifically created to increase children's interaction as a major part of their education. Keeping children interested and engaged in the learning process is vital for young age, so we have implemented the desired functionalities to stimulate that. They support the creation and presentation of rich learning content, like audio, video and text media, as well as interactive games and assessments. Our components have flexible configuration options and programming interface, so they can natively support advanced scenarios for personalization and dynamic updates in the learning objectives, approaches and content, based on the current needs of the user [3].

\section{E - Learning Software Requirements Specific for Children}

Latest research shows that kids in preschool age naturally interact with technologies in the same way they use their instincts to play with a new toy [4]. Another research in Australia, New Zealand, the United States of America and the United Kingdom has found out that it is easier for kids to use applications, than it is to tie their shoes or ride a bike [5]. Those indicate that children in preschool age do not need to develop preliminary skills for working with keyboard and a mouse, required by general purpose computing devices, in order to get specific interactive learning content. Despite that fact, at the moment there is a very small number of welldesigned learning management systems for kids [6], as most applications for kids are built for entertainment and do not offer any educational interaction. A major reason for this is the lack of official standards for assessing the quality of educational applications for kids, which leads to problems with the quality, presentation and relevancy of content for the specific age group.

The need for appropriate systems for management of learning resources is crucial, because they can drastically help and improve education for kids. The quality of such applications, targeted for young children, depends on two things: using information about the kid's learning progress when generating content, and containing interactive activities and user interface, suitable for children's cognitive and psychomotor development [7]. Accordingly to Parmar [8], software applications, appropriate for children in preschool age are: purposeful and educational; interactive, transparent and intuitive; encouraging control and collaboration between the teacher/parent and the child; and strengthening connections between home and school.
In addition to the above requirements, that type of software should cover several more specific requirements [9]. One of them is access and mobility - the access to these applications should be controlled but accessible for children, which makes it easy to use anywhere and anytime, when it is necessary. Use of interactive elements is also part of the requirements, because they allow children to immerse in the application, keep their attention and focus. That includes user interface elements like screen update, sliding photos, playing audio and video, and etc. Technologies play a major role in preparing young kids for their daily activities, developing their personal qualities, social and emotional skills, and it is important that these technologies offer learning content. Regular use of mobile devices makes kids more confident and they should be able to choose the way in which they use it, as supplementary means for education. This is where context-based learning, animated graphics, audio, video, different types of games and assessments can offer systematic, but on the other had informal education to kids. The tools we have developed, which are presented in this article use these techniques to allow kids to have fun and thus perceive and remember the learning material more easily.

\section{Tools for Creating and Presenting Learning Materials for Kids}

As a part of our research, we have reviewed some of the most popular e-Learning systems like Moodle, Canvas LMS, Blackboard and Classroom. Our investigation showed that even though these systems support many distance learning features, they are not suitable for realizing learning resources for kids in preschool. The main reason is that this particular age group requires learning material that stimulates phonetics, elementary mathematics, creativity and most importantly the imagination. Besides these functionalities, the mentioned generalpurpose systems lack the necessary level of interaction with the audience. A concrete example is the missing support for animations and rich text formatting of certain components, like answers for online assessments. While this will not disrupt the assessment process of older users, it will not be suitable for kids as they need colors, shapes, interaction, and animation functionalities. Kids learn using their senses and it is considered that eyesight and hearing are the most important senses for the learning process. E-Learning has a positive impact on education, because children develop better coordination between their hands and eyes, together with their motor skills. These abilities help them form clearer images of reality and improve their problem solving skills. 
The instruments we have developed and present in this paper are built accordingly to all contemporary e-learning standards, and their user interface design is compliant to the needs and abilities of the specific target age group [10]. In the following paragraphs we describe three types of tools for creating, editing and presenting materials through choosing, matching and ordering actions. They can be used not only for demonstrating specific knowledge, but also for individual assessment and progress tracking. The examples shown below belong to the fields of English language and mathematics, but our modules allow the creation of such resources from all applicable fields.

The first of the instruments is the "Multiple choice" component, used for creating activities in the form of questions that allow the user to choose an answer. Such activities can be used to present correct facts about a learning topic, but they are also a very effective way to test students' knowledge. One or more of the offered answers are correct, while the rest are used for distraction. Unlike general learning management systems, our component allows teachers to create questions and answers in different formats rich text (HTML), images or both, which makes it better understood by kids. Figure 1 shows how the component is visualized and presented to the learners - children in preschool age. After examining the larger question area, they can choose an answer by clicking with the mouse or touching the screen. The component will indicate whether they are correct or not by coloring the answer in green or red, showing additional movements from the avatar on the right and playing sounds.

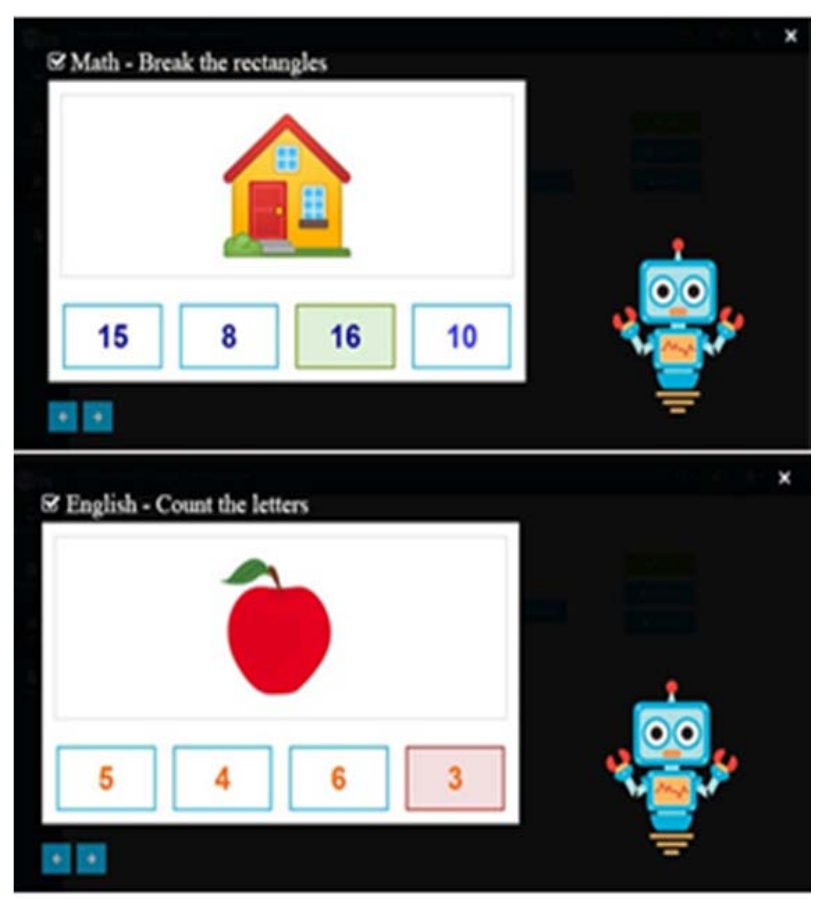

Figure 1. Multiple choice component example

The next component is the "Matching" component, used for creating activities that require the user to match pairs of related resources. That kind of activities improve the concentration and visual memory of the learners, increase the attention towards details, improve the ability for finding differences and similarities between objects, help in the classification of objects in trait groups and develop their vocabulary. The resources that can be visualized in this tool are rich text, images or both. Figure 2 shows several examples of a Matching game/assessment scenario containing supplementary resources in the fields of mathematics and English language. The main goal of the learner is to form correct pairs of tuples by using drag-and-drop functionality, which develops children's fine motor, visual and spatial skills by itself. The indication of a correct or incorrect result is given by colors, avatar animation and sounds like in the previous component.

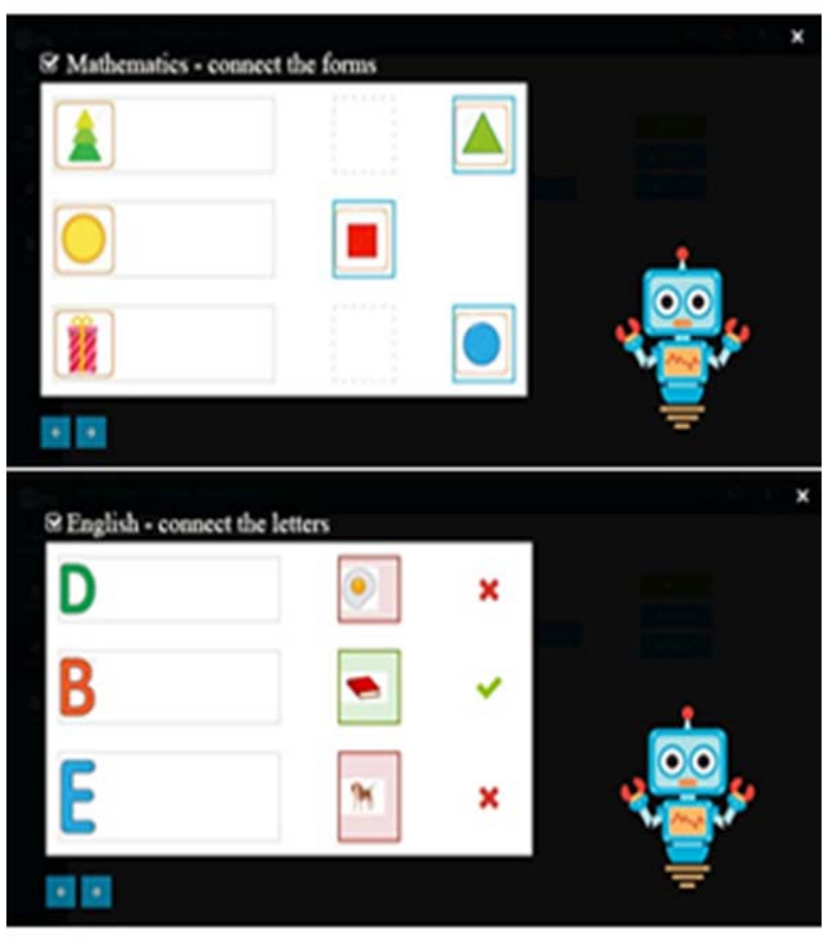

Figure 2. Matching component example

The last of the presented components allows implementing learning scenarios that require "Ordering" a set of objects in a correct sequence. Such activities help develop visual perceptual skills; logical thinking and memory, and the visual identification of patterns and relationships helps children understand the representation and problem solving mechanics. Sample learning goals include sorting by size and shape, ordering the letters in a word, numbers and other logical sequences of colors, characters and figures. That type of activity can also be used in more advanced scenarios like storytelling and ordering of historical and fictional events, which makes it applicable in all learning subjects. This instrument too supports both rich text and images in the question and answers sections. Figure 3 demonstrates some examples of Ordering activities, part of a learning process. 


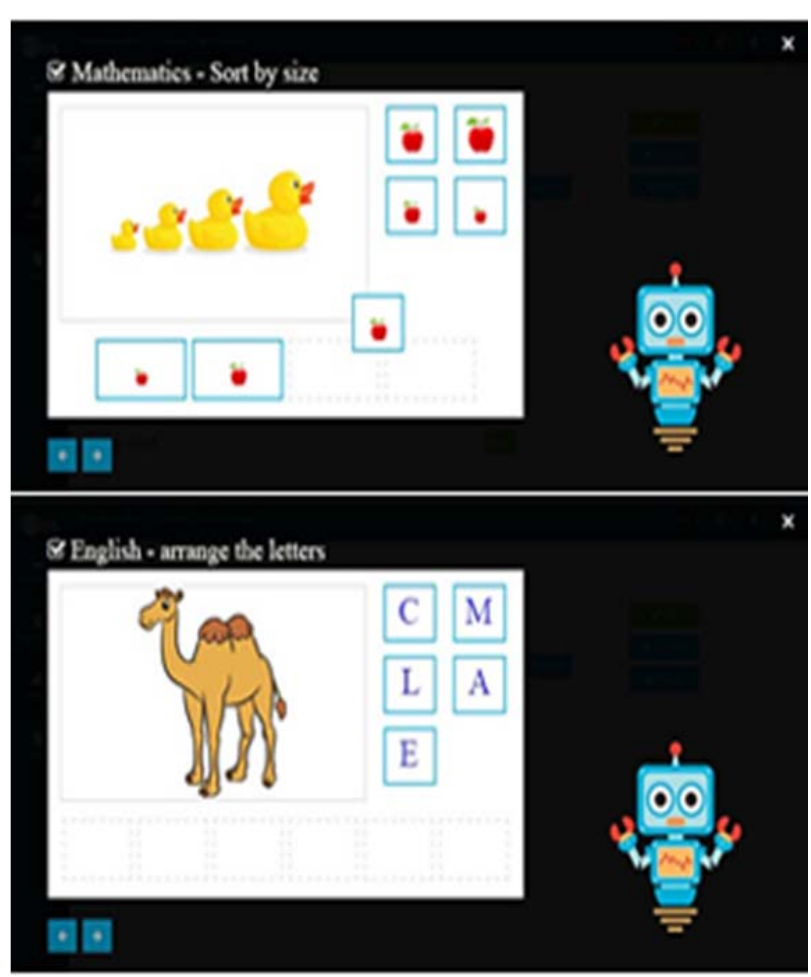

Figure 3. Ordering component example

The examples mentioned above show how the components are seen by the end users - the learning kids. Teachers and other content creators can use a different user-interface to create and/or edit the resources, which offers in-place editing of the question and answers areas by using rich text editors. Figure 4 shows the configuration of "Ordering" resources in action.

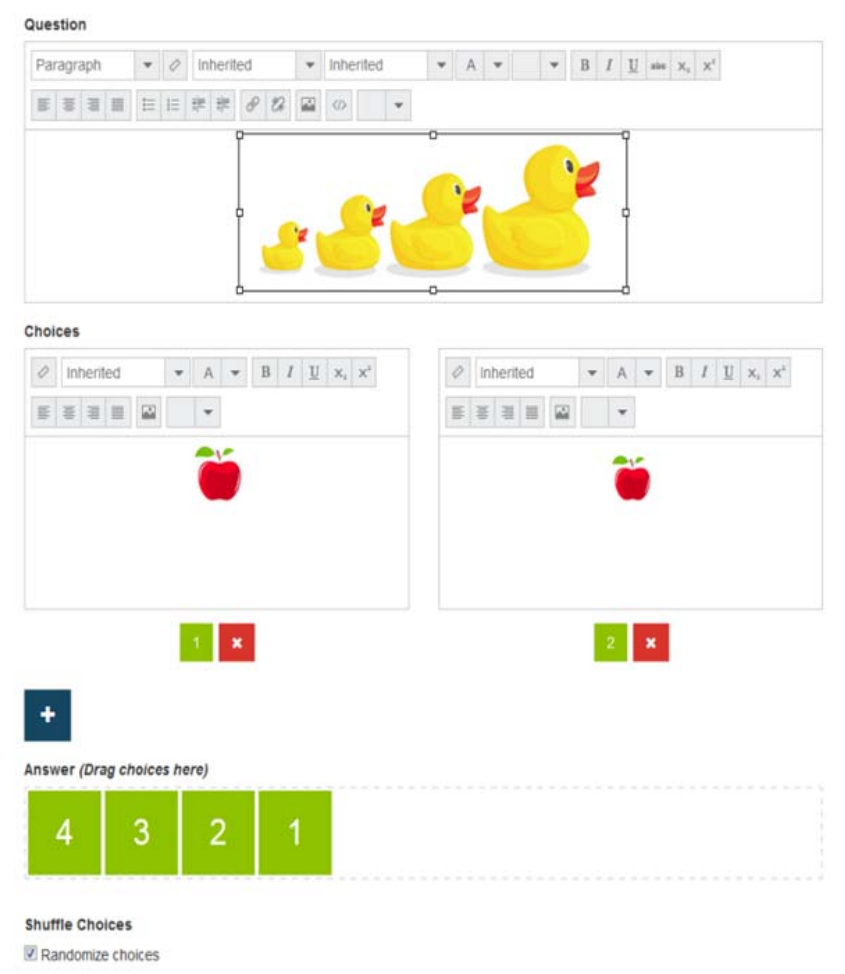

Figure 4. Creating an ordering resource
The editors used are part of the Shield UI JavaScript and HTML5 framework, which was selected because of the high levels of customization and extension supported (https://www.shieldui.com/). The default support for what-you-see-is-what-youget (WYSIWYG) editing was extended by adding custom features like automatic vertical and horizontal alignments, background of container elements and advanced image support. All parts of the user interface are built using the latest HTML5 standards, including accessibility support and responsive design. The tools we developed are general-purpose components that can be reused to create, edit and present interactive learning resources for kids, which belong to any subject, like mathematics, languages, social and applied sciences.

\section{Conclusion and Future Work}

In this article we presented a set of components for creating and presenting learning resources for children in preschool age. The instruments can be used by teachers and parents for increasing the knowledge and improving the learning process of kids, as well as integrated in various platforms for online education. Their main purpose is to help kids acquire key skills in a fun and entertaining way by using the latest technologies. As part of our research, we have demonstrated the tools to kindergarten and elementary school teachers, and we have received a positive feedback. Based on that, our next steps include testing the components in a real learning environment, as well as developing and integrating them into an online e-Learning platform for kids, and adding support for interactive 3D content.

\section{References}

[1]. Nikolova, A., \& Georgiev, V. A. (2017). Method for Assessing the Development of Children under Six Years of Age, Digital Presentation and Preservation of Cultural and Scientific Heritage, 7, 223-228.

[2]. Nikolova, A., Georgiev, V., \& Marinova, D. P. (2018). Using applications with digital culturalhistoric content for children development. In Edulearn 18. 10th International Conference on Education and New Learning Technology (Palma, 2nd-4th of July, 2018): conference proceedings (pp. 3954-3957). IATED Academy.

[3]. Pandey, A., (2017, August 29) Benefits Of Personalized eLearning - Featuring A Case Study For Instructional Designers. eLearning Industry.

Retrieved from:

https://elearningindustry.com/benefits-ofpersonalized-elearning-case-study-instructionaldesigners [accessed: 10 August 2020].

[4]. Sharkins, K. A., Newton, A. B., Albaiz, N. E. A., \& Ernest, J. M. (2016). Preschool children's exposure to media, technology, and screen time: Perspectives of caregivers from three early childcare settings. Early Childhood Education Journal, 44(5), 437-444. 
[5]. Grose, M. (2013). The good and the bad of digital technology for kids. Retrieved from:

https://narangbavalleyss.eq.edu.au/Supportandresourc es/Formsanddocuments/Documents/Parent $\% 20$ tips/di gital-technology-kids.pdf [accessed: 10 August 2020].

[6]. Hirsh-Pasek, K., Zosh, J. M., Golinkoff, R. M., Gray, J. H., Robb, M. B., \& Kaufman, J. (2015). Putting education in "educational" apps: Lessons from the science of learning. Psychological Science in the Public Interest, 16(1), 3-34.

[7]. Lanna, L. C., \& Oró, M. G. (2016). An analysis of the interaction design of the best educational apps for children aged zero to eight. Comunicar. Media Education Research Journal, 24(1).
[8]. Parmar N., (2012, Dec 14). Assessing the Quality of Apps for Usage with Young Children. Educational App Store Blog.

https://educationalappstore.wordpress.com/2012/12/1 4/assessing-the-quality-of-apps-for-usage-withyoung-children/ [accessed: 15 August 2020].

[9]. Papadakis, S., \& Kalogiannakis, M. (2017). Mobile educational applications for children: what educators and parents need to know. International Journal of Mobile Learning and Organisation, 11(3), 256-277.

[10]. Kosa, M., (2018, Jun 6). Children-first design: why UX for kids is a responsible matter, UX Collective. https://uxdesign.cc/ux-for-kids-responsible-matter802bd12fe28c [accessed: 15 August 2020]. 